\title{
Qualidade da semente do gergelim preto (Sesamum indicum L.) em diferentes épocas de colheita
}

Nobre, D.A.C. ${ }^{1 *}$; Trogello, E. ; Morais, D.L.B. ${ }^{2}$; Brandão Junior, D.S. ${ }^{3}$

'Universidade Federal de Viçosa - UFV. Av. P.H. Ralfs, s/n, Centro, CEP 36571-000, Viçosa-MG. '2Universidade Estadual de Montes Claros - Unimontes. Av. Reinaldo Viana, 2630 - Bico da Pedra, CEP 39440-000, JanaúbaMG. ${ }^{3}$ Instituto de Ciências Agrárias da Universidade Federal de Minas Gerais- ICA/UFMG, Av. Universitária, 1000 - Universitário, CEP 39.404-006, Montes Claros-MG. *danubia_nobre@yahoo.com.br

\begin{abstract}
RESUMO: O objetivo do presente estudo foi avaliar a qualidade da semente do gergelim preto colhida em diferentes épocas após a semeadura. As sementes utilizadas foram provenientes de quatro épocas de colheita (122, 129, 136 e 143 dias após semeadura). A avaliação da qualidade das sementes foi determinada pelo teste de germinação, primeira contagem de germinação, comprimento de plântulas, teste de condutividade elétrica, e massa de 100 sementes. Os dados foram submetidos à análise de variância, e, para avaliação da condutividade elétrica, utilizou-se esquema fatorial $4 \times 4$ (quatro épocas de colheita $x$ quatro tempos de embebição), as características significativas foram submetidas ao teste Tukey, a nível de $5 \%$ de significância. A época que propicia melhor qualidade das sementes de gergelim preto é evidenciada na colheita aos 136 dias após a semeadura. No entanto, deve-se considerar a padronização das épocas de colheita em função do estádio fisiológico da planta, uma vez que o número de dias para cada fase é específico para cada condição.
\end{abstract}

Palavras-chave: germinação, vigor, lixiviação.

ABSTRACT: Quality of black sesame seeds (Sesamum indicum L.) at different harvest times after sowing. The purpose of this study was to evaluate the quality of black sesame seeds harvested at different times after sowing. The seeds used were derived from four different harvest times (122, 129, 136 and 143 days after sowing). The assessment of the quality of the seeds was determined by standard germination, first count germination, seedling length, electrical conductivity and mass of 100 seeds. The data were submitted to variance analysis, and the evaluation of the electrical conductivity used a $4 \times 4$ factorial arrangement (four harvesting times $x$ four soaking times), the significant features were submitted to Tukey's test at $5 \%$ significance. The time that provides a higher quality of black sesame seeds is shown by the harvest at 136 days after sowing. However, the standardization of the harvest times due to the physiological stage of the plant should be considered, since the number of days for each phase is specific of each condition.

Keywords: germination, vigor, leaching.

O gergelim (Sesamum indicum L.) é uma das oleaginosas mais antigas cultivadas pelo homem (Beltrão et al., 2001), com semeadura em aproximadamente 6 milhões de hectares e produtividade média de $400 \mathrm{~kg} \mathrm{ha}^{-1}$, ocupando a nona posição, dentro do grupo das oleaginosas (Firmino et al., 2001). Dados mais recentes indicam que a produção mundial chega a 3,16 milhões de toneladas, semeados em 6,56 milhões de hectares e apresentando produtividade média de 481,40 $\mathrm{kg} \mathrm{ha}^{-1}$. Os maiores produtores são Myanmar
(867 mil toneladas), Índia (657 mil toneladas) e China (622 mil toneladas), representando 53,9\% da produção mundial. Dentro deste cenário, o Brasil é considerado um pequeno produtor, com 15 mil toneladas, produzidas em 25 mil hectares apresentando rendimento médio de $600 \mathrm{~kg} \mathrm{ha}^{-1}$ (Araújo et al., 2006).

Mais de $90 \%$ do gergelim produzido tem como destino o consumo alimentício (Kouri \& Arriel, 2009), uma vez que o mesmo é altamente nutritivo e medicinal. A cultura se apresenta como uma opção

Recebido para publicação em 16/07/2012

Aceito para publicação em 11/03/2013

Rev. Bras. Pl. Med., Campinas, v.15, n.4, p.609-616, 2013. 
de cultivo para o Semiárido Nordestino, podendo gerar renda além de ser fonte proteica. O gergelim é conhecido por apresentar baixo custo, ser de fácil utilização e em vários gêneros alimentícios, e de conter sabor e aroma agradáveis (Figueiredo \& Modesto Filho, 2008), o que estimula sua ampla utilização em todo território brasileiro. Desta forma, a cultura do gergelim vem assumindo grande importância econômica em território brasileiro, notadamente em sistemas agrícolas familiares (Queiroga et al., 2011). A adaptabilidade à agricultura familiar é evidenciada pela colheita essencialmente manual.

O óleo extraído de suas sementes apresenta elevada qualidade nutricional devido à presença de ácidos graxos insaturados, como oléico (47\%) e linoléico (41\%). É um óleo que apresenta características bastante interessantes do ponto de vista industrial, pois a presença de compostos secundários como o sesamol, confere ao óleo elevada estabilidade química evitando a rancificação (Beltrão et al., 1994).

Para que todas essas qualidades sejam mantidas, é importante que se faça o correto manejo da cultura, ressaltando ainda a colheita, sendo como uma das etapas mais importantes para o rendimento final, pois perdas de sementes podem acontecer em decorrência da abertura dos frutos após a maturação (Araújo et al., 2006).

A maturação dos frutos de gergelim ocorre de maneira assíncrona, e a deiscência das cápsulas ocorre da base para o ápice. A deiscência dos frutos é um complicador para o cultivo do gergelim, pois pequenos desvios em relação à época de colheita podem significar perdas de até $50 \%$ (Weiss, 1971). Para Araújo et al. (2006), na maturidade fisiológica as sementes atingem o máximo acúmulo de massa seca, geralmente coincidindo com o máximo de germinação e vigor (qualidade de sementes), no entanto, apresenta elevada umidade, o que é impróprio a sua conservação.

Segundo Queiroga et al. (2009), geralmente, a época do corte das plantas de gergelim é determinada pela maturação dos frutos da base do caule, mesmo que os frutos dos ápices do caule estejam imaturos, para prevenir a caída das sementes (frutos deiscentes). Portanto, o plantio do gergelim deiscente acima da capacidade de oferta de mão-de-obra pode resultar numa drástica perda de sementes durante a colheita manual, em função da abertura natural dos frutos na maturação, quando ainda na planta, os quais caem no chão pela simples ação do vento.

Cavalcanti (1994), afirma que o ponto de colheita ocorre quando a planta atinge a cor amarelada, as folhas caíram e os frutos ainda não secaram. Determinando assim, a antecipação da colheita para evitar perdas no campo. Terasawa et al. (2009) relatam que o momento ideal para a colheita de sementes seria na maturidade fisiológica, ou seja, imediatamente após se desligarem fisiologicamente da planta-mãe; a partir desse estádio, não ocorrem acréscimos significativos na massa seca das sementes. Portanto, Smiderle \& Pereira (2008), afirmam que colher na época certa é de fundamental importância para se obter um produto de melhor qualidade e com maior rendimento.

Visando contornar o problema com perdas devido à deiscência dos frutos por ocasião da colheita, produtores têm realizado a colheita antecipada, no entanto, podem ocorrer prejuízos de ordem qualitativa, como redução do teor de óleo e mudanças na composição de ácidos graxos (Lago et al., 2001). Deve-se ainda, atentar para o fato que as mudanças na qualidade fisiológica da semente podem comprometer a germinação no campo, uma vez que as sementes de gergelim são pequenas, e a germinação no campo tende a ser lenta. Assim, o estudo da melhor época de colheita, que consiga detectar as diferenças de vigor e de germinação são revestidos de importância para colher sementes de elevada qualidade fisiológica.

Lago et al. (2001), afirma que a questão do momento ideal de colheita da cultura se reveste de tamanha importância que, o próprio lançamento periódico de cultivares exige estudos sobre práticas culturais referentes ao momento adequado da colheita para maior produção e melhor qualidade das sementes. Neste sentido, o objetivo do trabalho foi avaliar a qualidade das sementes de gergelim preto em diferentes épocas de colheita após a semeadura.

As sementes de gergelim preto utilizadas neste estudo foram obtidas de uma área de plantio na região de Tiririca, município de Montes Claros MG, localizada à latitude de $16^{\circ} 44^{\prime} 06^{\prime \prime} \mathrm{W}$, longitude de $43^{\circ} 51^{\prime} 42^{\prime \prime} \mathrm{W}$ e altitude de 648 metros, na safra agrícola de 2010/11.

Os tratamentos empregados consistiram de quatro diferentes épocas de colheita das sementes (122, 129, 136 e 143 dias após semeadura - DAS) doravante denominadas $1^{\mathrm{a}}, 2^{\mathrm{a}}, 3^{\mathrm{a}}$ e $4^{\mathrm{a}}$ épocas de colheita. $O$ experimento foi desenvolvido em delineamento inteiramente casualizado com 4 repetições, totalizando 16 unidades experimentais.

O ponto de colheita foi determinado pela maturação fisiológica dos frutos, ou seja, quando os frutos da base das plantas iniciaram a abertura (deiscência dos mesmos). Neste momento, os ramos colhidos foram enviados ao Laboratório de Análise de Sementes do Instituto de Ciências Agrárias da UFMG, e as sementes foram removidas manualmente. Realizou-se a extração e limpeza manual das sementes, retirando-se as sementes chochas e as impurezas. 
A germinação das sementes foi determinada conforme as Regras para Análise de Sementes (Brasil, 2009), sendo utilizadas amostras de 50 sementes para cada repetição, colocadas sobre duas folhas de papel mata-borrão em caixas tipo gerbox. O papel mata-borrão foi umedecido com água destilada, utilizando-se um volume equivalente a 2,5 vezes o peso do papel. As caixas foram colocadas em câmara BOD previamente regulada à temperatura de $25^{\circ} \mathrm{C}$ e fotoperíodo de 12 horas. As avaliações foram realizadas ao terceiro e sexto dia após a montagem do teste, quando foram avaliadas as plântulas normais e anormais, sendo os resultados expressos em porcentagem.

Os resultados do teste de primeira contagem foram obtidos pelo número de plântulas normais, determinado por ocasião da primeira contagem do teste de germinação, ou seja, terceiro dia após a montagem e os dados expressos em porcentagem (Brasil, 2009).

Ao final do teste de germinação, foram escolhidas aleatoriamente dez plântulas consideradas normais de cada repetição, determinando-se o comprimento das mesmas com auxilio de uma régua milimetrada. Os resultados médios de cada repetição foram expressos em centímetros.

O teste de condutividade elétrica de massa foi realizado utilizando-se 4 repetições de 50 sementes. As sementes foram pesadas em balança analítica com precisão de $0,0001 \mathrm{~g}$ e colocadas para embeber em $50 \mathrm{~mL}$ de água deionizada ( $<2,0 \mu \mathrm{mhos} / \mathrm{cm}$ de condutividade elétrica), acondicionados em BOD, à temperatura constante de $25^{\circ} \mathrm{C}$ por diferentes períodos de embebição (2, 4,6 e 8 horas). A condutividade elétrica da solução foi medida através do condutivímetro MCA-150, com resultados expressos em $\mu \mathrm{S} \mathrm{cm}^{-1} \mathrm{~g}^{-1}$. Utilizou-se para isto um delineamento inteiramente cazualizado em esquema fatorial $4 \times 4$ (quatro épocas de colheita e quatro períodos de embebição das sementes) com quatro repetições, compondo 64 unidades experimentais.

Obteve-se ainda a massa de 100 sementes, as quais foram contadas ao acaso, manualmente, separando porções de "sementes puras". As amostras foram pesadas em balança de precisão $0,001 \mathrm{~g}$, e os valores médios expressos em gramas (g).

Os resultados foram tabulados e submetidos à análise de variância, sendo as características significativas em nível de $5 \%$ submetidas ao teste Tukey, ao nível de $5 \%$ de significância. As variáveis, germinação e vigor, tiveram os resultados em porcentagem transformados em arco seno $\sqrt{x / 100}$. Para as analises utilizou-se o aplicativo estatístico ASSISTAT desenvolvido por Silva \& Azevedo (2009).

Pode-se observar na Tabela 1 que, houve efeito significativo $(P<0,05)$ para o teste de germinação em função das diferentes épocas de colheita. Conforme apresentado, a $2^{a}, 3^{a}$ e $4^{a}$ época de colheita, possibilitaram maiores médias de germinação, porém, apenas a primeira época diferiu da terceira, não apresentando diferença para as demais. Os valores de germinação encontrados no presente estudo, para a $3^{a}$ época de colheita (136 DAS), foram próximos aos apresentados por Queiroga et al. (2010).

Lago et al. (2001), trabalhando com maturação e produção de gergelim 'IAC-China', observaram médias de 80,1 a 94,9\% de germinação quando produzidas no ano agrícola 1994/1995 e colhidas entre 79 a 144 dias após emergência; estes resultados são similares aos encontrados no presente estudo, exceto para as sementes colhidas aos 122 dias após semeadura, que apresentaram as menores médias de germinação, no entanto, Carvalho et al. (2001) apresentaram resultados similares a estes.

Ricci et al. (1999), avaliando a qualidade de sementes de gergelim secas no terreiro, com as hastes dispostas horizontalmente sobre telas de náilon e no campo, e no terreiro dispondo-se as hastes verticalmente em varais de arame e sobre lonas de polietileno, observaram que a germinação das sementes quando secadas no terreiro foi estatisticamente superior à das secas no campo. $\mathrm{O}$ que comprova a perda de qualidade das sementes quando submetidas a condições de campo após o ponto de maturidade fisiológica, já que a abertura dos frutos expõe às sementes as condições ambientais por vezes adversas. Reafirmando assim, a viabilidade da colheita quando realizada na época correta.

TABELA 1. Resultados médios de germinação $(G)$, primeira contagem de germinação (PC) e comprimento de plântulas (COMP), para os diferentes períodos de colheita das sementes de gergelim preto.

\begin{tabular}{lccc}
\hline Tratamentos & \multicolumn{3}{c}{ Variáveis } \\
& G (\%) & PC (\%) & COMP (cm) \\
\hline $1^{\circ}$ & $74,0 \mathrm{~b}$ & $67,0 \mathrm{~b}$ & $4,0 \mathrm{~b}$ \\
$2^{\circ}$ & $88,0 \mathrm{ab}$ & $71,0 \mathrm{~b}$ & $3,8 \mathrm{~b}$ \\
$3^{\circ}$ & $95,0 \mathrm{a}$ & $63,0 \mathrm{~b}$ & $5,6 \mathrm{a}$ \\
$4^{\circ}$ & $87,0 \mathrm{ab}$ & $87,0 \mathrm{a}$ & $4,2 \mathrm{~b}$ \\
Teste F & $7,375^{* *}$ & $22,396^{* *}$ & $16,242^{* *}$ \\
CV (\%) & 7,60 & 5,15 & 8,93
\end{tabular}

Médias seguidas de letras diferentes na coluna diferem entre si pelo teste de Tukey a $5 \%$ de probabilidade. ${ }^{* *}$ Significativo a $1 \%$. CV: Coeficiente de variação

Rev. Bras. Pl. Med., Campinas, v.15, n.4, p.609-616, 2013. 
O vigor das sementes, representado pelos testes de primeira contagem e comprimento de plântulas foi influenciado $(P<0,05)$ pelas diferentes épocas de colheita após a semeadura (Tabela 1). Os valores de porcentagem de plântulas normais obtidas por meio do teste de primeira contagem apresentaram as sementes colhidas aos 143 DAS, como as de maior média e diferente das demais. De acordo com os dados apresentados, a porcentagem de primeira contagem no presente estudo, foram superiores aos dados apresentados por Torres et al. (2009).

Sousa et al. (2011), observaram para sementes de coentro (Coriandrum sativum L.) colhidas em diferentes épocas, que o vigor decresceu, provavelmente devido a deterioração no campo, em decorrência do atraso na colheita. No presente estudo, observou-se elevação do vigor conforme foram sendo realizadas as colheitas, possivelmente pelo fato das sementes de gergelim preto ainda não terem atingido o ponto de maturidade fisiológica.

Para a variável comprimento de plântulas, foi verificado efeito significativo $(P<0,05)$ quando as sementes foram colhidas aos 136 dias após semeadura ( $3^{a}$ época). Segundo Azevedo et al. (2003), diferentes cultivares de gergelim apresentaram plântulas com tamanho médio de $4,78 \mathrm{~cm}$, sendo este valor, inferior ao encontrado no presente estudo (Tabela 1).

A germinação e o vigor (primeira contagem de germinação e comprimento de plântula) das sementes referentes à $4^{a}$ época de colheita do presente estudo, foram semelhantes aos resultados expresso por Queiroga et al. (2012), avaliando sementes de gergelim em diferentes posições da planta.
Em conformidade com as variáveis

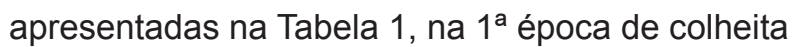
(122 DAS) as sementes de gergelim preto revelaram não terem ainda atingido a maturação fisiológica, devido à baixa qualidade das sementes quando comparada as demais épocas de colheita. Logo, iniciando-se a colheita no ponto de abertura dos frutos da base das plantas não houve efeito negativo na qualidade das sementes, para algumas épocas de colheita, conforme os dados apresentados. Para Marcos Filho (2005), o manejo durante a colheita incluindo a época e o método utilizado, exerce influência decisiva sobre a qualidade e quantidade do produto.

Pelo teste de condutividade elétrica (Figura 1), as sementes dos diferentes períodos de colheita, apresentaram a $4^{a}$ época, como sendo a menos vigorosa, já que apresentou as maiores médias de leitura, ou seja, maior quantidade de eletrólitos lixiviados, diferindo das demais épocas de colheita.

Como a degradação das membranas celulares se constitui, no primeiro evento do processo de deterioração das sementes (Delouche \& Baskin, 1973), os testes que avaliam a integridade das membranas tornam-se bastante sensíveis para estimação do vigor. Portanto, os menores valores correspondentes à menor liberação de exsudatos, indicam também alto potencial fisiológico (elevado vigor), revelando menor intensidade de desorganização das membranas célulares (Borsato et al., 2000).

Neste sentido, Tunes et al. (2010) em estudo com sementes de cevada, afirmam que a antecipação da colheita, entre 129 e 118 dias após a semeadura, favoreceu a qualidade fisiológica das sementes. Para Mazzani (1983) as plantas de gergelim colhidas mais tarde, quando os frutos da

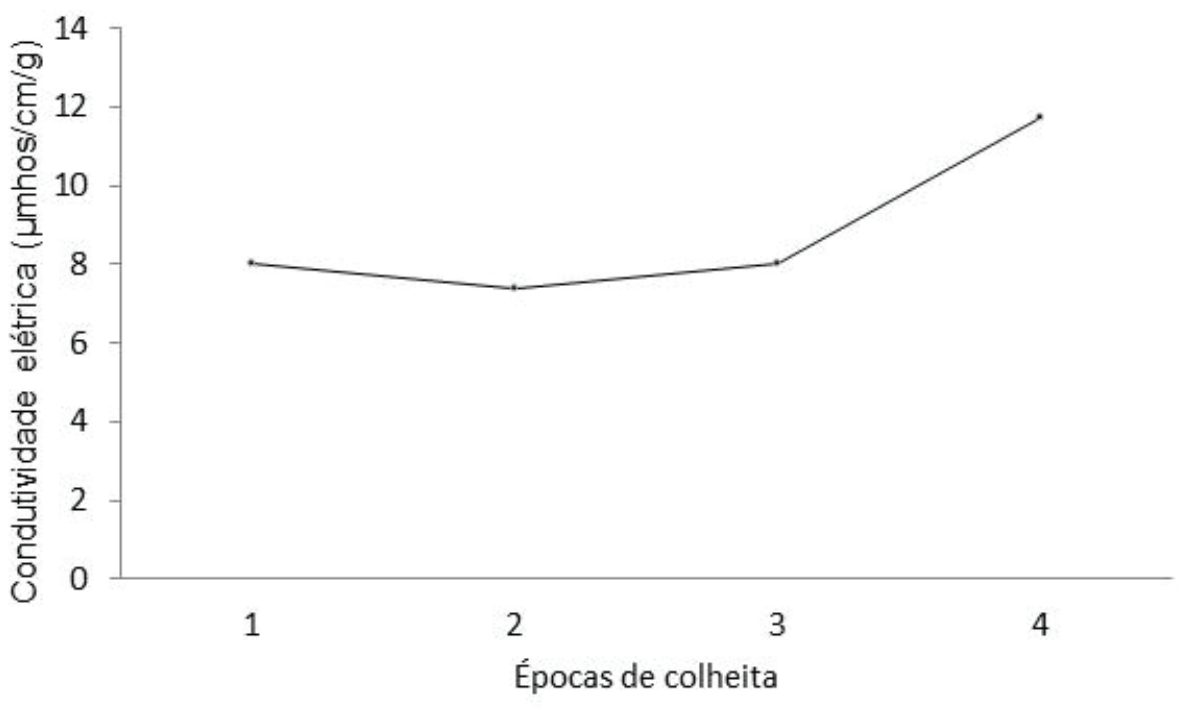

FIGURA 1. Condutividade elétrica em diferetes épocas de colheita (122, 129, 136 e 143 dias após semeadura) de Sesamum indicum $\mathrm{L}$.

Rev. Bras. PI. Med., Campinas, v.15, n.4, p.609-616, 2013. 
base das hastes começam a abrir-se, produzem sementes em maior número e de maior tamanho, sendo as perdas insignificantes. No entanto, fazem-se necessários estudos para a avaliação da qualidade fisiológicas dessas sementes.

Analisando os diferentes tempos de embebição em relação à condutividade elétrica (Figura 2), observa-se que, para o tempo de 2 horas de embebição, as sementes mostraram-se mais vigorosas, pois, apresentaram menores médias para quantidade de eletrólitos lixiviados. Para os demais tempos (4, 6 e 8 horas), a lixiviação de eletrólitos foi superior e diferente do tempo 2 horas. Portanto, estando, as sementes colhidas na $1^{\text {a }}$ época, com as membranas mais integras, permitem menor lixiviação de exsudados. Neste contexto, é importante ressaltar que, principalmente no início do processo de embebição, ocorre uma rápida e intensa liberação de eletrólitos até atingir o ponto de equilíbrio, quando as membranas celulares se reorganizam (Dias \& Marcos Filho, 1996), o que pode explicar a elevação na quantidade de eletrólitos, principalmente nas horas iniciais (2 a 4 horas).

Conforme Torres et al. (2009), em trabalho utilizando os tempos de embebição de 1 a 24 horas, há possibilidade do teste de condutividade elétrica ser realizado em menor tempo e, consequentemente, a obtenção de resultados mais rápidos, podendo ser utilizado o período de embebição de 8 horas. No presente estudo, observou-se que a redução no tempo pode ser de 2, 4, 6 ou 8 horas de embebição, exibindo ainda eficácia na distinção dos lotes.

O peso de 100 sementes (Figura 3 ) exibiu um rendimento satisfatório quando comparado aos resultados obtidos por Ricci (1999) para peso de mil sementes. $O$ presente trabalho verificou peso de 100 sementes superior apenas na $1^{\text {a }}$ época de colheita, quando os frutos foram colhidos aos 122 dias após a semeadura, com decréscimo lento do peso nas duas épocas subsequentes. Para os frutos colhidos na $4^{\mathrm{a}}$ época (143 DAS), o peso de 100 sementes revelou valores totais superiores aos observados na $2^{\mathrm{a}}$ e $3^{\mathrm{a}}$ época. Este acréscimo de peso pode estar relacionado às condições ambientais que as sementes foram expostas, como a precipitação pluviométrica. O excesso de umidade no meio externo e consequente absorção de água por parte das sementes pode mitigar a qualidade das mesmas, ficando evidente a necessidade de se adequar o período ideal de colheita, pois diante dos testes realizados, o efeito da germinação e do vigor das sementes de gergelim preto depende da época em que os frutos foram colhidos.

Conforme Carvalho \& Nakagawa (2000), durante a maturidade das sementes, ocorrem mudanças no desenvolvimento do embrião principalmente no teor de água, no tamanho, na massa da matéria seca, na germinação e no vigor. No entanto, o peso de matéria seca é o mais seguro indicador do estádio de maturação da semente.

Lago et al. (2001), avaliando o desenvolvimento e a qualidade física e fisiológica do gergelim cultivar IAC-China, colhidas em variadas épocas, concluíram que, o melhor período de colheita situou-se entre 116 e 132 dias após a emergência.

Estudos com diferentes cultivares venezuelanas de gergelim, apresentaram que a cultivar Glauca exibe o máximo de rendimento e

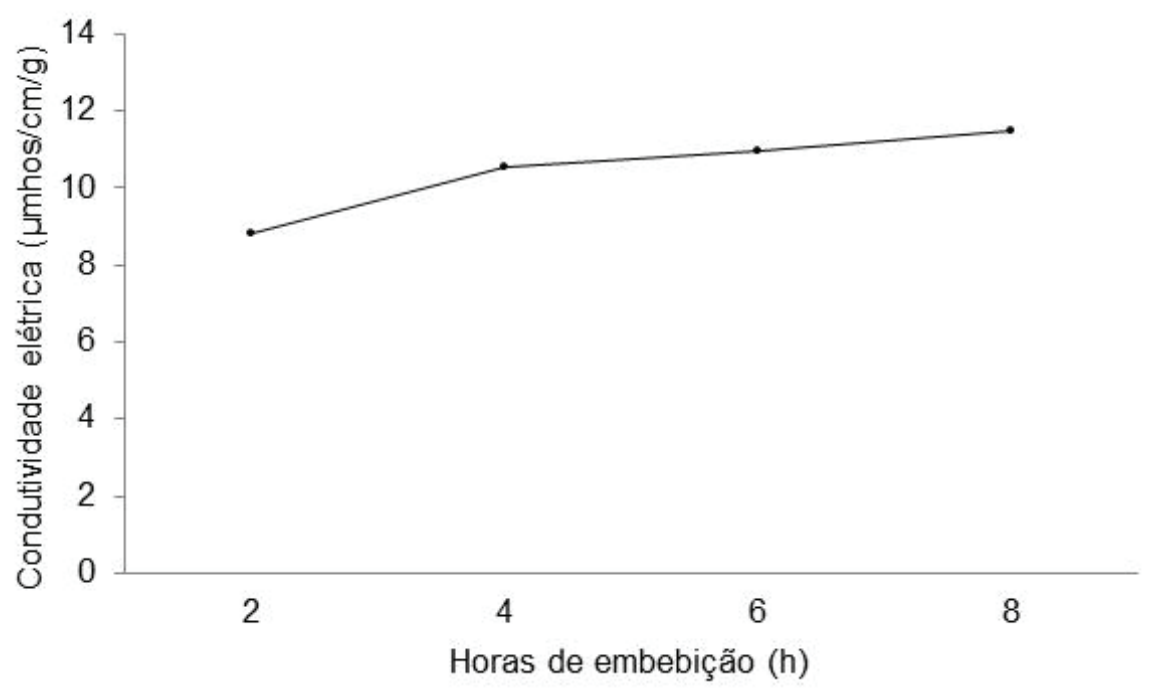

FIGURA 2. Condutividade elétrica em diferentes horas de embebição (2, 4, 6 e 8 h) de sementes de Sesamum indicum $\mathrm{L}$.

Rev. Bras. PI. Med., Campinas, v.15, n.4, p.609-616, 2013. 


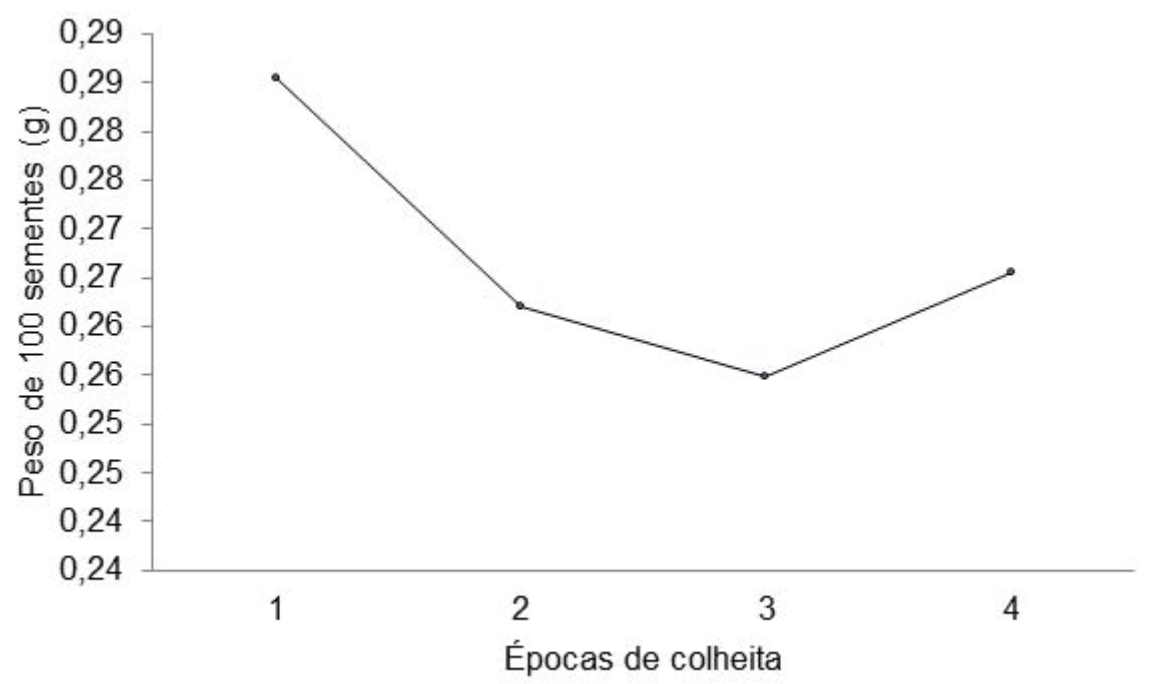

FIGURA 3. Peso de 100 sementes de Sesamum indicicum L. em diferentes épocas de colheita (122, 129, 136 e 143 dias após semeadura).

tamanho de grãos, quando colhida aos 97 dias após a semeadura enquanto que a cultivar Aceitera, os picos produtivos foram obtidos quando colhida aos 89 dias após a semeadura (Mazzani \& Allievi, 1966). Para o cultivar IAC-Ouro implantada em território brasileiro, Savy Filho et al. (1983; 1988; 1998), indicam épocas de colheita variando de 95 a 115 dias após a emergência.

A fase de colheita caracteriza-se pelo amarelecimento inicial e queda das folhas, com mudança de cor verde para amarelo ou marrom (Rincón \& Salazar, 1997; Savy Filho et al., 1998). Queiroga et al. (2009) afirmam que, geralmente, a época do corte das plantas de gergelim é determinada pela maturação dos frutos da base do caule, mesmo que os frutos dos ápices do caule estejam imaturos, para prevenir a caída das sementes (frutos deiscentes). Determinando assim, a antecipação da colheita para evitar perdas.

O melhor período para colheita depende ainda da interação genótipo $x$ ambiente. O gergelim G-3, quando produzido em Planaltina-DF, apresenta ciclo de 120 dias; 110 dias em Brasília-DF; 135 dias em Cristalina-GO (Spehar \& Trecenti, 2011). Para Lago et al. (1994), as épocas ótimas e práticas de colheita do gergelim 'IAC-Ouro', nas quais ocorreram as maiores produções de sementes e menores perdas por degrana, foram aquelas entre 90 e 95 dias após a emergência, no ano agrícola $87 / 88$ e entre 100 e 105 dias em 88/89. As sementes colhidas nestes intervalos, depois de adequada secagem, exibiram de bons a excelentes índices de emergência em casa-de-vegetação logo após a colheita e oito meses após o armazenamento em condições ambientais não controladas.
Diante do exposto, as sementes de gergelim preto produzidas no norte de Minas Gerais, revelaram boa qualidade fisiológica, sendo este fator dependente da época de colheita, já que, sementes que ficam expostas as condições de campo por períodos mais prolongados, sofrem com variações de umidade em seu interior, o que pode mitigar a qualidade das mesmas. Desta forma, assim como observado em outras culturas, a colheita próxima ao ponto de maturação garante maior qualidade das sementes.

A época que propicia maior qualidade de sementes de gergelim preto é evidenciada na colheita aos 136 dias após a semeadura, e deve-se optar por uma padronização de épocas de colheita por períodos fisiológicos da planta, uma vez que os valores numéricos de dias diferem de condição para condição.

\section{AGRADECIMENTOS}

Ao CNPq, a CAPES e a UFMG, pelo apoio financeiro e estrutural para desenvolvimento do presente trabalho.

\section{REFERÊNCIA}

ARAÚJO, A.E; SOARES, J.J; BELTRÃO, N.E.M; FIRMINO, P.T. Cultivo do Gergelim. n. 6, 2006. Disponível em: http://sistemadeproduçao.cnptia.embrapa.br/ fonteshtml/gergelim. Acesso em 20/04/2008.

AZEVEDO, M.R.Q.A. ALMEIDA, F.A.C.; GOUVEIA, J.P.G.; AZEVEDO, C.A.V.; SILVA, M.M.; PORDEUS, R.V. Germinação e vigor no desenvolvimento inicial do gergelim: efeito da salinidade da água de irrigação. Revista Brasileira de Produtos Agroindustriais, v. 5,

Rev. Bras. PI. Med., Campinas, v.15, n.4, p.609-616, 2013. 
n. 2, p.167-172, 2003.

BELTRÃO, N.E. de M.; FREIRE, E.C.; LIMA, E.F. Gergelim cultura no trópico semi-árido nordestino. Campina Grande: EMBRAPA-CNPA, Circular Técnica, 18. 1994. 52p.

BELTRÃO, N.E.M; SOUZA, J.G; PEREIRA, J.R. Fitologia In: O Agronegócio do gergelim no Brasil. Embrapa Informação Tecnológica, Embrapa Algodão/Campina Grande, 348p, 2001.

BORSATO, A.V. BARROS, A. S. DO R.; AHYENS, D. C.; DIAS, M. C. L. DE L. Avaliação de testes de vigor para sementes de aveia-branca (Avena sativa L.). Revista Brasileira de Sementes, v. 22, n. 1, p. 163-168, 2000.

BRASIL. Ministério da Agricultura, Pecuária e Abastecimento. Regras para Análise de Sementes. Ministério da Agricultura, Pecuária e Abastecimento. Secretaria de Defesa Agropecuária. Brasília: Mapa/ ACS, 2009. 399 p.

CARVALHO, N.M.; NAKAGAWA, J. Sementes: ciência, tecnologia e produção. 4.ed. Jaboticabal: FUNEP, 2000. 588p.

CARVALHO, P.G.B.; BORGHETTI, F.; BUCKERIDGE, M.S.; MORHY, L.; FERREIRA FILHO, E.X. Temperaturedependent germination and endo-â-mannanase activity in sesame seeds. Revista Brasileira de Fisiologia Vegetal, v. 13, n. 2, p. 139-148, 2001.

CAVALCANTI, J. O cultivo do gergelim no sertão do São Francisco. Comunicado técnico, Petrolina-PB, n. 43, p. 1-3, 1994.

DELOUCHE, J.C.; BASKIN, C.C. Accelerated aging techniques for predicting the relative storability of seed lots. Seed Science and Technology, v. 1, n. 2, p. 427452, 1973.

DIAS, D.C.F.S.; MARCOS-FILHO, J. Testes de condutividade elétrica para avaliação do vigor de sementes de soja (Glycine max (L.) Merril). Scientia Agrícola, v. 53, n. 1, p. 31-42, 1996.

FIGUEIREDO, A.S.; MODESTO FILHO, J. Efeito do uso da farinha desengordurada do Sesamum indicum $L$. nos níveis glicêmicos em diabéticas tipo 2. Revista Brasileira de Farmacognosia, v. 18, p. 77 83, 2008.

FIRMINO, P.T.; ARRIEL, N.H.C.; ARRUDA, T.A.; ANTUNES, R.M.P. Valor proteico do grão, importância na alimentação humana e aplicações na fitoterapia e fitocosmética. In: BELTRAO, N.E. de M.; VIEIRA, D.J. (Ed.). $O$ agronegócio do gergelim no Brasil. $E$ Embrapa Informação Tecnológica, Embrapa Algodão/ Campina Grande, 2001. p. 303-325.

KOURI, J.; ARRIEL, N.H.C. Aspectos econômicos. In: ARRIEL, N.H.C.; BELTRÃO, N.E. de M.; FIRMINO P. de T. (Ed.). Gergelim: o produtor pergunta, a Embrapa responde. Brasília: Embrapa Informação Tecnológica; Campina Grande: Embrapa Algodão, 2009. p.193 209. (Coleção 500 perguntas, 500 respostas).

LAGO, A.A. DO; CAMARGO, O. B. A.; FILHO, A.S.; MAEDA, J.A. Maturação e produção de sementes de gergelim cultivar IAC-China. Pesquisa Agropecuária Brasileira, Brasília, v. 36, n. 2, p. 363-369, 2001.

LAGO, A.A.; SAVY FILHO, A.; BANZATTO, N.V.; CAMARGO, O.B.A. Maturação e produção de sementes do gergelim 'IAC-Ouro'. Revista Brasileira de Sementes, v. 16, n. 2, p. 134-137, 1994.

MARCOS FILHO, J. Fisiologia de sementes de plantas cultivadas. Piracicaba: Fealq, 2005. 495 p.

MAZZANI, B. Pedaliáceas oleaginosas. (Ed.). Cultivo y mejoramiento de plants oleaginosas. Caracas: Centro Nacional de Investigaciones Agropecuárias, 1983. p.169-226.

MAZZANI, B.; ALLIEVI, J. Efectos de diferentes épocas de cosecha sobre los rendimientos y algunas características de la semilla de ajonjolí (Sesamum indicum L.). Agronomía Tropical, v. 16, n. 3, p. 223-228, 1966.

QUEIROGA, V.P.; GONDIM, T.M.S.; QUEIROGA, D.A.N. Tecnologias sobre operações de semeadura e colheita para a cultura do gergelim (Sesamum indicum L.). Revista Agro@mbiente, v. 3, n. 2, p. 106-121, 2009.

QUEIROGA, V.P.; BORBA, F.G.; ALMEIDA, K.V.; SOUSA, W.J.B.; JERÔNIMO, J.F.; QUEIROGA, D.A.N. Qualidade fisiológica e composição química das sementes de gergelim com distintas cores. Revista Agro@mbiente, v. 4, n. 1, p. 27-33, 2010.

QUEIROGA, V.P.; FIRMINO, P.T.; GONDIM, T.M.S.; SILVA, A.C.; VALLE, D.G.; QUEIROGA, D.A.N.; PE. GEREON, H.G.M. Soluções tecnológicas em prol da coletividade para sustentabilidade da cadeia produtiva do gergelim orgânico da agricultura familiar piauiense. Revista Brasileira de Produtos Agroindustriais, v. 13, n. 1, p. 97-111, 2011.

QUEIROGA , V.P.; FREIRE, R.M.M.; FIRMINO, P.T.; MARINHO, D.R.F.; SILVA, A.C.; BARBOSA, W.T.; QUEIROGA, D.A.N. Qualidade de sementes de gergelim de diferentes posições na planta em comparação a colheita convencional. Tecnologia \& Ciência Agropecuária, v. 6, n. 2, p. 41-47, 2012,

RICCI, A.B.; GROTH, D; LAGO, A.A. Densidade de plantas, secagem e produção de sementes de gergelim cv IAC-China. Revista Brasileira de Sementes, v. 21, n. 1, p. 82-86, 1999.

RINCÓN, C. A.; SALAZAR, N. Descripción de las etapas del desarrollo del ajonjolí. Agronomía Tropical, v. 47, n. 4, p. 475-487, 1997.

SAVY FILHO, A.; BANZATTO, N. V.; LASCA, D. H. C. Gergelim 'IAC-Ouro'. Campinas: CECOR-DEXTRU/ CATI, 1983. (Folder).

SAVY FILHO, A.; BANZATTO, N. V.; VEIGA, R. F. de A. Descrição morfológica do gergelim (Sesamum indicum L.) 'IAC-Ouro'. Campinas: Instituto Agronômico. Boletim Científico, 13. 1988. 12 p.

SAVY FILHO, A.; CAMARGO, O.B.A.; BANZATTO, N.V. Gergelim (Sesamum indicum L.). In: FAHL, J.I.; CAMARGO, M.B.P.; PIZZINATO, M.A.; BETTI, J.A.; MELO, A.M.T.; DEMARIA, I.C.; FURLANI, A.M.C. Instruções agrícolas para as principais culturas econômicas. 6.ed. rev. atual. Campinas: Instituto Agronômico, Boletim, 200. 1998. 396 p.

SILVA, F.A.S.E.; AZEVEDO, C.A.V. Principal Components Analysis in the Software AssistatStatistical Attendance. In: WORLD CONGRESS ON COMPUTERS IN AGRICULTURE, 7, Reno-NVUSA: American Society of Agricultural and Biological Engineers, 2009.

SMIDERLE, O.J., PEREIRA, P.R.V.S. Épocas de colheita e qualidade fisiológica das sementes de arroz irrigado cultivar BRS 7 Taim, em Roraima. Revista Brasileira de Sementes. v. 30, n. 1, p. $74-80,2008$.

SOUSA, T.V.; ALKIMIM, E.R.; DAVID, A.M.S.S.; SÁ, J.R.;

Rev. Bras. PI. Med., Campinas, v.15, n.4, p.609-616, 2013. 
PEREIRA, G.A.; AMARO, H.T.R.; MOTA, W.F. Época de colheita e qualidade fisiológica de sementes de coentro produzidas no norte de Minas Gerais. Revista Brasileira de Plantas Medicinais. v. 13, n. spe, p. 591-597. 2011.

SPEHAR, C.; TRECENTI, R. Desempenho agronômico de espécies tradicionais e inovadoras da agricultura em semeadura de sucessão e entressafra no cerrado do planalto central brasileiro. Bioscience Journal, v. 27, n. 1, p. 102-111, 2011.

TERASAWA, J.M.; PANOBIANCO, M.; POSSAMAI, E.; KOEHLER, H.S. Antecipação da colheita na qualidade fisiológica de sementes de soja. Bragantia. v. 68 , n. 3 , p. 765-773, 2009.

TORRES, S.B.; MEDEIROS, M.A.; TOSTA, M.S.; COSTA, G.M.M. Teste de condutividade elétrica em sementes de gergelim. Revista Brasileira de Sementes, v. 31, n. 3, p. 70-77, 2009.

TUNES, L.M.; BARROS, A.C.S.A.; BADINELLI, P.G.; GARCIA, D.C. Diferentes épocas de colheita e qualidade fisiológica de sementes de cevada. Revista Brasileira de Sementes. v. 32, n. 2 p. 42-48, 2010.

WEISS, E. A. Castor, sesame and saf flower. London: Leonard Hill, 1971. 901p. 